\title{
A study of fetal umbilical artery and middle cerebral artery doppler velocimetry before and after treatment of severe maternal iron deficiency anaemia
}

\author{
Suhail Rafiq, Sheema Posh, Irtifa Jeelani, Musaib Ahmad Dar, Shahnaz Tang \\ Corresponding author: Dr. Sheema Posh, Senior Resident, Department of Obstetrics and \\ Gynaecology, SKIMS, India; Email : Sheema.posh@gmail.com
}

Distributed under Attribution-Non Commercial - Share Alike 4.0 International (CC BY-NC-SA 4.0)

\begin{abstract}
Objective: To evaluate the effect of vascular adaptation and extent of compensatory changes in the fetus with the change in maternal $\mathrm{Hb}$ levels and to study maternal and perinatal outcome after treatment of maternal iron deficiency anaemia. Methods: The present study was an observational prospective study conducted on 50 pregnant women from January 2016 to June 2017. The study population was divided into two groups: group A - patients with moderate anaemia (Hb: 7- $9 \mathrm{gm} / \mathrm{dl})$ and group B - patients with severe anaemia $(\mathrm{Hb}<7 \mathrm{gm} / \mathrm{dl})$. Group A received parenteral iron preparation and group B received blood transfusion or packed RBCs until $\mathrm{Hb}$ exceeded $7 \mathrm{gm} / \mathrm{dl}$, then parenteral iron was used. Maternal $\mathrm{Hb}$ and color doppler were performed before and after treatment of anaemia. Results: There was a significant increase in $\mathrm{Hb}$ levels in all patients after treatment of anaemia (p-value 0.018). There was a decrease in the umbilical artery RI after treatment of maternal anaemia in both the groups and the decrease was more in those who received blood transfusion. A comparison for UA RI for both the groups before and after treatment was statistically significant $(\mathrm{p}=0.032$ for group $\mathrm{A}$ and $\mathrm{p}=0.0001$ for group $\mathrm{B}$ ). There was an improvement in MCA RI in both the groups after treatment of anaemia (the p-value for group A and group B being 0.001 and 0.0001 respectively i.e. statistically significant). The $\mathrm{C} / \mathrm{U}$ ratio was normalized to $>1.1$ in both the study groups after treatment of anaemia (p- value in group A being 0.653) and group B being 0.0001(statistically significant) respectively. After treatment of iron deficiency anaemia, normalization of doppler indices was observed. Conclusion: Our data support the fact that maternal haemoglobin content of $<7 \mathrm{~g} / \mathrm{dl}$ is strongly associated with marked fetal hemodynamic adaptation and must be treated with acute red cell transfusion. Moderate anaemia $(>7 \mathrm{~g} / \mathrm{dl})$ is not sufficient to trigger fetal blood flow redistribution and can be treated with parenteral iron.
\end{abstract}

Keywords: Anaemia, haemoglobin $(\mathrm{Hb})$, doppler ultrasound, maternal outcome, fetal outcome.

The WHO defines anaemia in pregnant women as haemoglobin level below $11 \mathrm{~g} / \mathrm{dl}$. According to Centres for Disease Control (CDC) (1998), anaemia in iron supplemented pregnant women is described as $\mathrm{Hb}$ below $11 \mathrm{~g} / \mathrm{dl}$ in the first and third trimesters, and $10.5 \mathrm{~g} / \mathrm{dl}$ in the second trimester. It also recommends that haemoglobin in pregnant women should not be allowed to fall below $10.5 \mathrm{~g} / \mathrm{dl}$ in the $2 \mathrm{nd}$ trimester, taking into account the physiological changes of pregnancy ${ }^{1}$. Indian Council of Medical Research (ICMR) classifies anaemia as mild (9 -
$10.9 \mathrm{~g} / \mathrm{dl})$, moderate $(7-9 \mathrm{~g} / \mathrm{dl})$, severe $(<7 \mathrm{~g} / \mathrm{dl})$ and very severe $(<4 \mathrm{~g} / \mathrm{dl})^{2}$.

The effect of maternal anaemia on the fetus and the newborn varies depending on the severity of anaemia. Preterm birth, intrauterine growth restriction, neonatal anaemia and stillbirth are the possible foetal complications of anaemia. Besides the severity of maternal anaemia, the gestational period at which the fetus is exposed to low maternal haemoglobin levels is also important in deciding the perinatal outcome ${ }^{3}$.

Received: $26^{\text {th }}$ November 2020, Peer review completed: $11^{\text {th }}$ February 2021, Accepted: $3^{\text {rd }}$ March 2021.

Rafiq S, Posh S, Jeelani I, Ahmad Dar M, Tang S. A study of fetal umbilical artery and middle cerebral artery doppler velocimetry before and after treatment of severe maternal iron deficiency anaemia. The New Indian Journal of OBGYN. 2022; 8(2): 174 - 79. 
Color Doppler ultrasound provides a convenient and effective method to assess the hemodynamic status of fetal circulation in relation to fetal hypoxia and thereby facilitates the monitoring of the fetus, prediction of adverse outcome and thus, timely treatment so as to improve survival prognosis of the fetus ${ }^{4}$.

Distribution of fetal blood flow (between the placental and cerebral regions) is determined by middle cerebral artery resistivity index/umbilical artery resistivity index $(\mathrm{C} / \mathrm{U}$ resistance ratio), which is the ratio between the cerebral resistance index (CRI) and umbilical resistance index (URI). This parameter is always $>1.1$ during normal pregnancy, but decreases in case of hypoxia because of the increase in URI (due to increase in placental resistance) and decrease in CRI (due to cerebral vasodilatation) ${ }^{5}$. At the same time, vasodilatation of the fetal middle cerebral artery (MCA) occurs resulting in the so called "brain sparing effect" (compensatory flow or adaptation changes) ${ }^{6,7}$.

The volume of umbilical artery increases with advancing gestation hence the high vascular resistance detected in first trimester gradually decreases. This decrease in the vascular resistance allows a continuous forward blood flow in the umbilical artery throughout cardiac cycle ${ }^{8}$. The normal UA waveform usually has a "Saw-Tooth" pattern with flow always in the forward direction. The impedance in UA is measured by resistivity index (RI) which decreases from 0.756 to 0.609 in normal pregnancy. An abnormal waveform shows absent or reversed diastolic flow. In pregnancies complicated by maternal anaemia, there is reduction in end diastolic flow causing an increase in RI values followed by absent end-diastolic flow $(\mathrm{RI}=1)$ and finally reversal of end-diastolic flow ${ }^{9}$.

The cerebral circulation is normally a high impedance circulation with continuous forward flow throughout the cardiac cycle ${ }^{10}$. The MCA RI shows a biphasic trend with RI values being low in early as well as in late gestation due to the increased metabolic requirements of the brain during these periods. The normal value of MCA RI is 0.787 at 18 weeks, gradually increasing to 0.91 at 30 weeks. Thereafter, it again shows a falling trend and decreases to 0.785 at 40 weeks ${ }^{11}$. In case of severe maternal anaemia, there is increase in end diastolic flow which leads to decrease in MCA-RI values ${ }^{10,12,13}$.

Distribution of fetal blood flow is determined by the $\mathrm{C} / \mathrm{U}$ resistance ratio, which is the ratio between the MCA RI and URI. This parameter is always $>1.1$ during normal pregnancy but decreases in case of anaemia because the URI increases while the CRI decreases ${ }^{14}$.
As severe maternal anaemia triggers a marked fetal cerebral vasodilatation, the haemoglobin has to be recovered as soon as possible in order to suppress the cerebral vasodilatation. Moderate maternal anaemia does not trigger fetal flow redistribution or abnormal FHR changes which suggest that fetal oxygenation remains satisfactory ${ }^{7}$. This study attempts to show the impact of maternal iron deficiency anaemia on the mother and the fetus and whether treatment can reverse the physiological and pathological effects of anaemia on the mother as well as the foetus.

\section{Methodology}

This prospective study was conducted on pregnant women attending postgraduate department of obstetrics and gynaecology (Government Medical College and Associated Hospitals, Srinagar) for a period of 18 months from January 2016 to June 2017. The population consisted of 50 patients with 25 patients in moderate anaemia group and 25 in severe anaemia group which were defined as under: group A patients with moderate anaemia ( $\mathrm{Hb} 7-9 \mathrm{gm} / \mathrm{dl})$ and group B - patients with severe anaemia $(\mathrm{Hb}<7 \mathrm{gm} / \mathrm{dl})$. The inclusion criterias were women with gestational age $>26$ weeks, singleton pregnancy and women with anaemia $(\mathrm{Hb}<10 \mathrm{~g} / \mathrm{dl})$. Exclusion criterias were women with age $<20$ years or $>35$ years, dead fetus, multiple pregnancies, history of recent blood transfusion, vitamin deficiencies, cardiovascular diseases like cyanotic heart disease, heart failure or pulmonary hypertension, infections and chronic inflammation.

Doppler study of the umbilical artery RI, fetal middle cerebral artery RI and MCA RI/ UA RI (C/U resistance ratio) was done. Maternal venous sample was taken for haemoglobin level. Group A received parenteral iron preparation after calculation of iron deficiency using the formula: Total iron dose $=$ Body weight* (Target Hb-Present $\mathrm{Hb}$ in $\mathrm{g} / \mathrm{dl})^{*} 2.4+500 \mathrm{mg}$. Iron sucrose was administered in $500 \mathrm{cc}$ saline over one hour and repeated every other day. Group B received blood transfusion or packed RBCs until $\mathrm{Hb}$ exceeded $7 \mathrm{gm} / \mathrm{dL}$, then parenteral iron was used.

Maternal $\mathrm{Hb}$ level, iron profile, ultrasound and color doppler were repeated after completion of treatment. After delivery, Apgar score, NICU admissions, preterm births, acute fetal distress (meconium staining), fetal growth restriction, and the number of perinatal deaths were assessed. The doppler examination was done twice i.e., on the day of admission and after completion of treatment. 
Data has been statistically described in terms of range, mean \pm standard deviation ( \pm SD) for continuous variables and frequencies (number of cases) and percentages for categorical variables. Comparison of numerical variables between the study groups was done using unpaired ' $t$ ' test and chi-square test in comparing pre and post treatment values.

\section{Results}

In our study, the age of patients ranged from 22-35 years of age with maximum number of patients in 25-35 years age group. The mean age of patients was $29.56 \pm 3.09$ years in group A and $29.24 \pm 2.27$ years in group B (table 1). The mean gestational age of our patients on admission was $35.6 \pm$ 1.80 weeks in group A and $35.84 \pm 1.67$ weeks in group B which is almost same in both the groups (table 1). In the

Table 1: Demographic profile of the study population

\begin{tabular}{llll} 
Categories & Group A & Group B & p-value \\
\hline Mean age (years) & $29.56 \pm 3.09$ & $29.24 \pm 2.27$ & 0.679 \\
Parity (mean) & $1.92 \pm 0.95$ & $2.36 \pm 1.75$ & 0.176 \\
Mean gestational age (by dates) on admission (weeks) & $35.6 \pm 1.80$ & $35.84 \pm 1.67$ & 0.630 \\
Mean gestational age (by ultrasound) at delivery(weeks) & $36.52 \pm 0.91$ & $36.08 \pm 1.75$ & 0.272 \\
\hline P-value is significant if $<0.05$. & & & \\
\hline
\end{tabular}

Table 2: The mean of haemoglobin levels between the two groups.

\begin{tabular}{llllllll}
\hline Parameters & \multicolumn{3}{c}{ Group (A) } & \multicolumn{2}{c}{ Group (B) } & $\begin{array}{c}\text { P } \\
\text { value }\end{array}$ \\
\cline { 2 - 6 } & $\mathbf{N}$ & Mean & $\begin{array}{c}\text { Standard } \\
\text { Deviation }\end{array}$ & N & Mean & $\begin{array}{c}\text { Standard } \\
\text { Deviation }\end{array}$ & \\
\hline Mean $\mathrm{Hb} \%$ on admission $(\mathrm{g} / \mathrm{dl})$ & 25 & 7.59 & 0.42 & 25 & 6.06 & 0.61 & 0.0001 \\
Mean $\mathrm{Hb} \%$ after treatment $(\mathrm{g} / \mathrm{dl})$ & 25 & 10.15 & 0.47 & 25 & 10 & 0.40 & 0.2306 \\
Change $\mathrm{In} \mathrm{Hb}(\mathrm{g} / \mathrm{dl})$ & & 2.56 & & & 3.94 & & 0.018 \\
\hline
\end{tabular}
$\mathrm{C} / \mathrm{U}$ ratio in group $\mathrm{A}$ and group $\mathrm{B}$ before and after treatment of anaemia was 0.653 (statistically insignificant) and 0.0001 (statistically significant) respectively (figure 5). After treatment of iron deficiency anaemia, present study, most of the patients were primigravida in group A and multigravida in group B (table 1).

There was a significant increase in $\mathrm{Hb}$ levels in all patients after treatment of anaemia (table 2). There was a decrease in the umbilical artery RI after treatment of maternal anaemia in both the groups and the decrease was more in those who received blood transfusion.

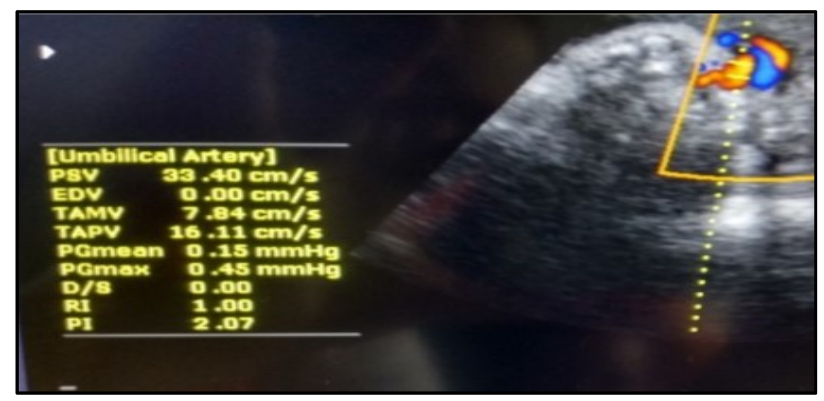

Figure 1: Color doppler image with spectral waveform of umbilical artery showing high resistance flow with decreased diastolic flow. normalization of doppler indices was observed. This suggests that color doppler can be used for improving perinatal outcome in maternal iron deficiency anaemia.

The majority of the patients were delivered by normal vaginal delivery. In our study, $80 \%$ patients of group A had vaginal delivery among which $64 \%$ had spontaneous delivery and in $20 \%$ patients labour was induced. The remaining $20 \%$ patients were delivered by caesarean section. In group $\mathrm{B}, 76 \%$ patients had vaginal delivery which included $44 \%$ spontaneous and $32 \%$ induced deliveries.

The difference in Apgar score for the two groups was statistically insignificant $(p>0.05)$ (table 4). The percentage of foetuses with preterm births, FGR and AFD was higher in those with severe maternal anaemia (table 5). Preterm births occurred in $9(36 \%)$ patients while as in group B, they occurred in $8(32 \%)$ patients with the difference between the two groups being statistically insignificant $(p=0.765)$. In group A, FGR occurred in $2(8 \%)$ babies and in group B, 


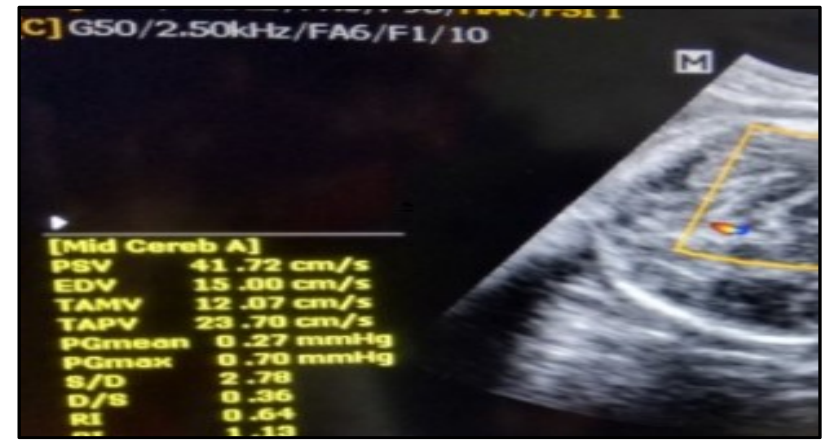

Figure 2: Color doppler image with spectral waveform of Middle Cerebral artery showing low resistance flow with increased diastolic flow (Brain Sparing).

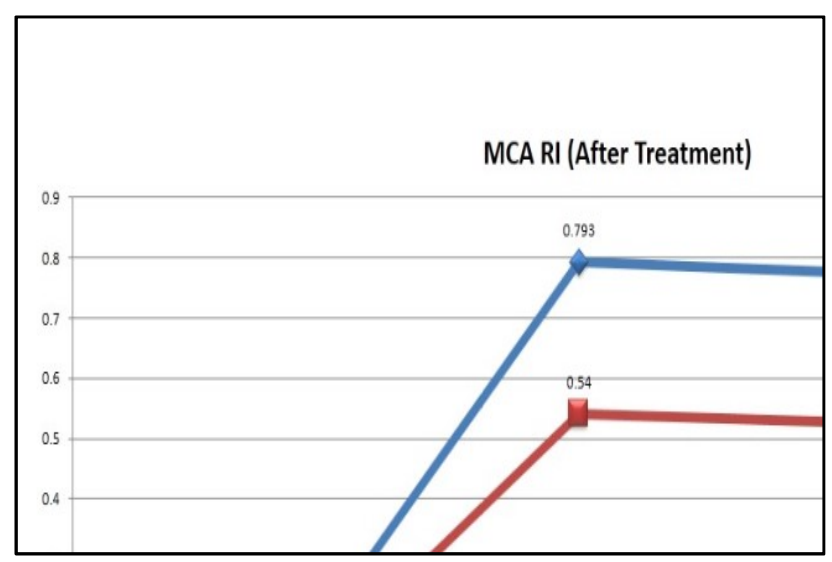

Figure 3: Continuous line diagram showing distribution of resistance index of MCA before treatment.

Table 4: Apgar score

\begin{tabular}{llllllll}
\hline \multirow{2}{*}{$\begin{array}{l}\text { Gestational age } \\
\text { (in weeks) }\end{array}$} & \multicolumn{3}{c}{ Group A } & \multicolumn{3}{c}{ Group B } & \multirow{2}{*}{ P-Value } \\
\cline { 2 - 7 } $26-32$ & $\mathbf{N}$ & Mean & SD & N & Mean & SD & - \\
$33-36$ & 9 & - & - & $1^{*}$ & - & - & - \\
$>36$ & 9 & 0.68 & 0.05 & 7 & 0.67 & 0.138 & 0.113 \\
\hline
\end{tabular}

Table 5: Perinatal outcome

\begin{tabular}{|c|c|c|c|c|c|c|c|c|}
\hline \multirow[b]{2}{*}{ Parameters } & \multicolumn{2}{|c|}{ Preterm births } & \multicolumn{2}{|c|}{ FGR } & \multicolumn{2}{|c|}{ AFD } & \multicolumn{2}{|c|}{ Perinatal deaths } \\
\hline & $\begin{array}{l}\text { Group A } \\
\text { N }(\%)\end{array}$ & $\begin{array}{l}\text { Group B } \\
\text { N }(\%)\end{array}$ & $\begin{array}{l}\text { Group A } \\
\text { N (\%) }\end{array}$ & $\begin{array}{l}\text { Group B } \\
\text { N (\%) }\end{array}$ & $\begin{array}{l}\text { Group A } \\
\text { N (\%) }\end{array}$ & $\begin{array}{l}\text { Group B } \\
\text { N }(\%)\end{array}$ & $\begin{array}{l}\text { Group A } \\
\text { N }(\%)\end{array}$ & $\begin{array}{l}\text { Group B } \\
\text { N }(\%)\end{array}$ \\
\hline Adverse outcome was present & $9(36 \%)$ & $8(32 \%)$ & $2(8 \%)$ & $9(36 \%)$ & $3(12 \%)$ & $9(36 \%)$ & $1(4 \%)$ & $6(24 \%)$ \\
\hline Adverse outcome was not present & $16(64 \%)$ & $17(68 \%)$ & $23(92 \%)$ & $16(64 \%)$ & $22(88 \%)$ & $16(64 \%)$ & $24(96 \%)$ & $19(76 \%)$ \\
\hline P-value & 0.765 & & 0.016 & & 0.046 & & 0.041 & \\
\hline
\end{tabular}

$9(36 \%)$ babies had FGR with the difference between the two groups being statistically significant $(\mathrm{p}=0.016)$. In group $\mathrm{A}$, AFD was present in $3(12 \%)$ babies and in group B in 9 (36\%) babies with the difference between the two groups being statistically significant $(\mathrm{p}=0.046)$. In group $\mathrm{A}$, perinatal death was found in $1(4 \%)$ patient while as in group $\mathrm{B}$ it was found in $6(24 \%)$ patients with the difference between the two groups being statistically significant $(\mathrm{p}=0.041)$.

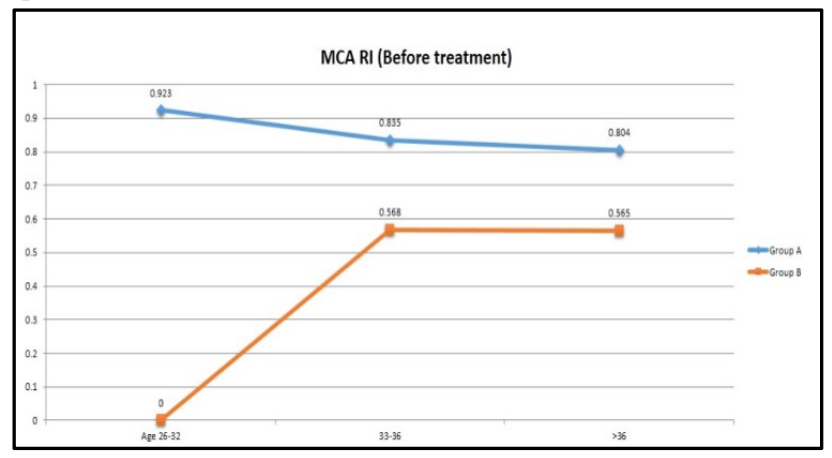

Figure 4: Continuous line diagram showing distribution of resistance index of MCA after treatment.

\section{Discussion}

Maternal iron-deficiency anaemia is a worldwide medical complication leading to adverse effects both in the mother as well as the foetus ${ }^{15}$. In our study, there is no correlation between the severity of maternal anaemia with age, gestational age at admission or delivery date. Our findings were similar to the study conducted by Milan Stefanovic et al ${ }^{16}$ who reported that the maternal age and gestational age were similar in both moderate and severely anaemic pregnant women. In our study, severe anaemia affected primiparous women less than multiparous women. Similar findings were reported by EO Uche-Nwachi et al ${ }^{17}$. There was a significant increase in $\mathrm{Hb}$ levels in all patients after treatment of anaemia. Similar findings were reported by Milan Stefanovic et al ${ }^{16}$.

There was a decrease in the umbilical artery RI after treatment of maternal anaemia in both the groups and the decrease was more in those who received blood transfusion. These findings were consistent with those of Ghada A, Abdel Moety, and Yossra et al ${ }^{18}$. There was an increasing trend in MCA RI in both the groups after treatment and the increase was statistically significant. This was consistent with the study conducted by Milan Stefanovic et al ${ }^{16}$ and E Ancuta et al ${ }^{19}$ who reported a similar decrease in MCA RI. The $\mathrm{C} / \mathrm{U}$ ratio was normalized to $>1.1$ in both the study groups after treatment of anaemia. Our observations were consistent with the findings of Milan 
The New Indian Journal of OBGYN. 2021 (January-June);8(2)

Stefanovic et al ${ }^{16}$ and E Ancuta et al ${ }^{19}$ who reported that the $\mathrm{C} / \mathrm{U}$ ratio was restored to normal in both moderate and severely anaemic patients after treatment. Our findings were also consistent with those of Ghada A, Abdel Moety, and Yossra et al ${ }^{18}$.

Majority of patients in both the groups delivered vaginally. This can be explained by the fact that a few of them had preterm births and vaginal delivery was preferred in anaemic patients as blood loss is less in vaginal delivery as compared to caesarean section. These findings are similar to those of Chhabra et al ${ }^{20}$. It was found that the Apgar score of newborns in group B was less as compared to group A in the gestational age of 33-36 weeks. Our findings were consistent with those of Ghada A, Abdel Moety, and Yossra et al ${ }^{18}$ who reported that low Apgar scores resolved in majority of the foetuses after treatment of anaemia and Toral $\mathrm{M}$ Goswami et al ${ }^{21}$ reported an increased Apgar score in non-anaemic patients as compared to anaemic patients.

The fetal prognosis was assessed in terms of the number of preterm births, FGR, AFD and perinatal deaths. The percentage of foetuses with preterm births was higher in those with severe maternal anaemia. Our findings were similar to those of Chhabra $\mathrm{S}$ et al ${ }^{20}$ and $\mathrm{K}$ Jagadish Kumar et $\mathrm{al}^{22}$. In our study, risk of FGR increased with increasing severity of anaemia. Our findings were consistent with those of Chhabra $\mathrm{S}$ et al ${ }^{20}$. In our study, higher percentage of babies with AFD in severely anaemic mothers was reported. These findings were in contrast to those of Ramya Sundaram et al ${ }^{23}$ who reported no significant association between maternal anaemia and passage of meconium by the foetuses. Also higher number of perinatal deaths was reported in severely anaemic mothers. Similar findings were reported by Goswami M et al ${ }^{20}$ and Nair M et al ${ }^{24}$.

\section{Conclusion}

Our data support the fact that maternal haemoglobin content of $<7 \mathrm{~g} / \mathrm{dl}$ is strongly associated with marked fetal hemodynamic adaptation and must be treated with acute red cell transfusion. Moderate anaemia $(>7 \mathrm{~g} / \mathrm{dl})$ is not sufficient to trigger fetal blood flow redistribution and can be treated with parenteral iron. Close monitoring of the fetal umbilical and cerebral circulation by doppler examination in anaemic pregnancies allows the measurement of the amplitude of the fetal vascular response, early assessment of fetal damage and helps in improving fetal outcome as well.

\section{Conflict of interest: None. Disclaimer: Nil.}

\section{References}

1. Centres for Disease Control and Prevention. CDC criteria for anaemia in children and childbearing-aged women. Morb Moral Wkly Rep. 1989; 38: 400.

2. Koller $\mathrm{O}$. The clinical significance of hemodilution during pregnancy. Obstet Gynaecol Surv. 1982; 37: 649 .

3. Kalaiwani K. Prevalence and consequences of anaemia in pregnancy. Indian J Med Res. 2009; 130: 627-33.

4. Sumpaico WW, Leung KY, Malhotra N, et al. Doppler evaluation in fetal hypoxia. Ultrasound in Obstetrics and Gynaecology. 1991; 252: 500.

5. Lackman F, Capewell V, Gagnon R, Richardson B. Fetal umbilical cord oxygen values and birth to placental weight ratio in relation to size at birth. Am J Obstet Gynecol. 2001; 185: 674-82.

6. Vyas S, Nocolaides KH, Campbell S. Middle cerebral artery flow velocity waveforms in fetal hypoxaemia. $\mathrm{Br}$ J Obstet Gynecol. 1990; 97: 797-803.

7. Vyas S, Nicolaides K, Campbell S. Doppler examination of the middle cerebral artery in anaemic foetuses. Am J Obstet Gynecol. 1990; 162: 1060-4.

8. Khare M, Paul S, Konje J. Variation in Doppler indices along the length of the cord from the intraabdominal to the placental insertion. Acta Obstet Gynecol Scand. 2006; 85: 922-8.

9. Schwarze A, Gembruch U, Krapp M, et al. Qualitative venous Doppler waveform analysis in preterm intrauterine growth restricted with ARED flow in the umbilical artery-correlation with short-term outcome. Ultrasound Obstet Gynaecol. 2005; 25: 573-9.

10. Morrow RJ, Adamson SL, Bull SB, et al. Effect of placental embolization on the umbilical arterial velocity waveform in fetal sheep. Am J Obstet Gynecol.1989; 161:1055.

11. Veille JC, Hanson R, Tatum K. Longitudinal quantitation of middle cerebral artery blood flow in normal human fetuses. Am J Obstet Gynecol. 1993; 169: 1393.

12. Mari G, Deter RL. Middle cerebral artery flow velocity waveforms in normal and small-for-gestational fetuses. Am J Obstet Gynecol.1992;166:1262.

13. Arbielle P, Carles G, Bousquet F, Body G and Lansac J. Fetal cerebral and umbilical artery blood flow changes during pregnancy complicated by malaria. Ultrasound Med. 1998; 17 (4): 223-9.

14. Soothill PW, Ajayi RA, Campbell S, et al. Relationship between fetal acidaemia at cordocentesis and subsequent 
The New Indian Journal of OBGYN. 2021 (January-June);8(2)

neurodevelopment. Ultrasound Obstet Gynecol.1992; 2: 80 .

15. Centers for Disease Control and Prevention (CDC). Recommendations to prevent and control iron deficiency in the United States. Morb Mortal Wkly Rep. 1998; RR3: 1-29.

16. Stefanović M, Milosavljević M, Radović-Janošević D, Kutlešić R, Vukomanović P, et al. Maternal anaemia and fetal cerebral hemodynamic response-Doppler assessment. Medicine and Biology. 2005; 12(2): 93-6.

17. Uche-Nwachi EO, Odekunle, Singh R. Anaemia in pregnancy: associations with parity, abortions and child spacing in primary healthcare clinic attendees in Trinidad and Tobago. Afr Health Sci. 2010 Mar; 10(1): 66-70.

18. Ghada A, Moety A, Ahmed YS. Effect of Maternal Iron Deficiency Anaemia on Fetal Cerebral Haemodynamic Response by Doppler and APGAR Score. Med J Cairo Univ. 2012 June; 80(1): 235-40.

19. Ancuta E, Ancuta C, Ioirdache C, Chirieac R. Predictive value of Doppler Assessment for the Fetal Umbilical and Cerebral Haemodynamic response in anaemic pregnancies. Ultrasound in Obstetrics and Gynaecology. 2009; 34 (Suppl 1): 177-84.

20. Chhabra S, Chopra S. Mid Pregnancy Fetal Growth Restriction and Maternal Anaemia - a Prospective Study. J Nutr Disorders and Therapy. 2016; 6(2):187.
21. Goswami TM, Patel VN, Pandya N, etal. Maternal anaemia during pregnancy and its impact on perinatal outcome. International Journal of Biomedical and Advance Research. 2014; 5(2): 99-102.

22. Kumar KJ, Asha N, Sujatha MS, Manjunath VG. Maternal Anaemia in Various Trimesters and its Effect on Newborn Weight and Maturity. Int J Prev Med. 2013 Feb; 4(2): 193-9

23. Sundaram R, Murugesan A. Risk factors for meconium stained amniotic fluid and its implications. International Journal of Reproduction, Contraception, Obstetrics and Gynecology. 2016 Aug; 5(8): 2503-6.

24. Nair M, Choudhury MK, Kakoty SD. Association between maternal anaemia and pregnancy outcomes: a cohort study in Assam, India. BMJ Global Health. 2016; 1(1): e000026.

\footnotetext{
Suhail Rafiq ${ }^{1}$, Sheema Posh ${ }^{2}$, Irtifa Jeelani ${ }^{3}$, Musaib Ahmad Dar ${ }^{3}$, Shahnaz Tang ${ }^{4}$

${ }^{1}$ Senior Resident, Department of Radiodiagnosis and Imaging, GMC Srinagar, India; ${ }^{2}$ Senior Resident, Department of Obstetrics and Gynaecology, SKIMS, India; ${ }^{3}$ Senior Resident, Department of Obstetrics and Gynaecology, SKIMS, India; ${ }^{4}$ Senior Resident, Department of Radiodiagnosis and Imaging, GMC Srinagar, India; ${ }^{5}$ Professor, Department of Obstetrics and Gynaecology, LD hospital GMC Srinagar, India.
} 